\title{
Antonio Gramsci e a questão feminina
}

Daniela Mussi*

https://orcid.org/0000-0002-5845-0317

Um labirinto para a "questão feminina"

Em 8 de fevereiro de 1929, Antonio Gramsci escreveu na prisão as primeiras linhas daqueles que viriam a ser conhecidos por Quaderni del Carcere $^{1}$. Nelas, apresentou de maneira sumarizada dezesseis "argumentos principais" de pesquisa, nenhum dos quais dedicados especificamente à questão feminina ( $\mathrm{Q} 1, \mathrm{p} .5)$. O tema, contudo, apareceu discutido de maneira diluída entre os parágrafos escritos em cadernos miscelânea entre dezembro de 1929 e julho de 1930 e dedicados aos temas "da função da imigração", "questão sexual", "feminismo" e "americanismo " ( $\mathrm{Q} 1, \$ \$ 37,61,63$, 146 e 158 ; Q $3, \$ 62)^{2}$.

A primeira referência ao tema foi indireta, no parágrafo 37 do Q 1 , escrito entre dezembro de 1929 e fevereiro de 1930. Neste, Gramsci criticou o "mau gosto" intelectual do dirigente socialista Filippo Turati, recuperando sarcasticamente, para tal, o discurso parlamentar de setembro de 1919 de Turati sobre o direito ao voto feminino e das prostitutas, as "assalariadas do amor" (Q 1, \$37, p. 27). Esse tema

* Universidade de São Paulo, São Paulo, Brasil.

1. Os parágrafos dos Quaderni del Carcere de Antonio Gramsci estão citados conforme a edição curada por Valentino Gerratana (1975) e aparecem indicados no formato Q X, §y, p. z.

2. Todos parágrafos “A”, ou seja, de primeira versão que aparecem com nova redação posteriormente (textos “C”). Neste caso, especialmente no Quaderno 22 ( $\$ \$ 61,62,146$ e 158$)$, escrito no segundo semestre de 1934, e no Quaderno 28 ( $\$ 37)$, escrito nos primeiros meses de 1935. 
apareceu, também, no parágrafo 63 do Q 1 (p. 74), escrito entre fevereiro e março de 1930, em que Gramsci discutiu a capacidade de intelectuais como Turati penetrarem nos meios proletários onde "os autodidatas são especialmente levados, por ausência de um hábito científico e crítico", a se encantarem com certas “fantasias”, já que "a falta de sobriedade e de ordem intelectual leva também à desordem moral", especialmente no plano da "questão sexual", sendo especialmente impactante para a "pouca participação das mulheres na vida coletiva”.

No parágrafo 61 do Q 1, do mesmo período, Gramsci desenvolveu o que entende ser a "questão sexual” em relação ao "americanismo". Nesta, Gramsci comparou os Estados Unidos e a Itália a respeito da "composição da população" e sua relação com a industrialização. Na Itália, observou, a composição da população se tornara “insalubre' devido à imigração e baixa ocupação das mulheres nos trabalhos produtivos"; já nos Estados Unidos, “a adaptação psicofísica à nova estrutura industrial não levou ainda a um florescimento 'superestrutural', não colocou ainda a questão fundamental da hegemonia” ( $\mathrm{Q} 1, \$ 61, \mathrm{pp} .70-72$ ). A participação das mulheres no trabalho produtivo, somada à imigração, comparava, eram fatores de uma relação "desfavorável" entre a população italiana "potencialmente ativa e aquela passiva”, enquanto nos Estados Unidos a "hegemonia nasce da fábrica” (Idem, p. 72). Esta é a primeira passagem nos Quaderni del Carcere em que Gramsci fala “das mulheres”, sinalizando os efeitos de um problema "econômico" amplamente discutido no ambiente comunista pós-1917 - o da (não) inclusão feminina na atividade industrial - no equilíbrio "superestrutural” italiano.

No Q $1, \$ 62$, de fevereiro-março de 1930, Gramsci deixou indicados os contornos analíticos da "questão sexual" e algumas hipóteses a seu respeito (Q 1, §62, pp. 72-74). O parágrafo começa pontuando a “obsessão” dos “projetistas” em resolver a questão sexual e a presença determinante desse tema nas diversas "utopias", o que poderia estar relacionado ao fato de que toda "sociedade em desenvolvimento" reprime os “instintos sexuais". A seu ver, toda nova fase de regulação "não natural” é acompanhada, como expressão de suas formas de resistência, de apelos à "natureza" (entre os quais Gramsci elencou a psicanálise "freudista”). Da apreciação econômica mais "externa" do problema - ligada estritamente ao desenvolvimento do mundo econômico - Gramsci desloca a reflexão para a relação entre cidade e campo para destacar as semelhanças (e mesmo a agudeza) dos "crimes" sexuais e do "bestialismo" sexual no ambiente rural em relação ao urbano. Em ambos, contudo, a sexualidade desemboca no dualismo que se cristaliza no "ideal estético feminino" como "reprodutora" versus "brinquedo" (Ibidem).

Além disso, identificou uma dimensão "interna” da função reprodutiva - que mais tarde passaria a chamar por "molecular" - associada à trajetória do núcleo familiar 
e à sua relação com o aumento da média de vida e a baixa natalidade em contraste com a "consciência instintiva" dos mais jovens desta como um problema ("velhos sem filhos são tratados como os "bastardo'”"). O aspecto-chave, aqui, é identificar "a questão sexual como uma 'questão econômica' específica, que coloca os problemas coordenados do tipo de superestrutura", chegando até mesmo a impor "um aspecto de problema nacional” (Ibidem). O exemplo de Gramsci, agora, é o caso francês e o conflito progressivo entre as gerações mais antigas em "relação anormal com as gerações jovens de mesma estirpe", cada vez menores, combinado com o surgimento de novas divisões do trabalho (devido ao preenchimento das ocupações não qualificadas por massas de imigrantes).

A questão sexual era, nesse caso, "um problema de hegemonia" cuja ausência de solução levava a um "problema econômico grave, já que o aprendizado "hereditário" contínuo, indispensável para a adaptação à vida industrial, passa a ser sistematicamente interrompido pelos conflitos geracionais e pelos fluxos migratórios. Assim, a percepção da natureza fundamentalmente hegemônica do problema estaria no coração da preocupação precoce dos “industriais americanos", destacadamente Henry Ford, com "as relações sexuais de seus dependentes". Por fim, algo que não aparecia no esforço interessado desses reguladores era muito caro a Gramsci já nessas primeiras reflexões carcerárias sobre a questão sexual:

A questão mais importante é a salvaguarda da personalidade feminina: até que as mulheres alcancem verdadeiramente uma independência frente aos homens, a questão sexual será rica de características mórbidas e será preciso cautela em tratá-la e tirar conclusões legislativas ( $\mathrm{Q}$ $1,62 \S$, p. 73, grifo nosso).

Em março de 1930, ainda, Gramsci comentou, no e $1 \$ 146$, uma resenha do livro Mulher. Uma defesa [Woman. A vindication], escrito pelo conservador inglês Anthony M. Ludovici em 1923, autor também de Man's descent from the Gods e The false assumptions of democracy ( $\mathrm{Q} 1, \$ 146, \mathrm{p} .130)$. Em seu livro, Ludovici se opunha à ideia de que "a expansão da industrialização e do comércio das mulheres" teria trazido "progresso" inevitável para a Europa Ocidental, pois havia fomentado entre as mulheres a busca pela "autonomia" e "liberdade" (Ludovici, 1923, p. VII, 29). Para o filósofo antidemocrático, "más-adaptações" sociais, frutos da perda de controle e orientação pelos homens, haviam degenerado as mulheres (Idem, p. 29). "Me coloco entre os antifeministas", concluía o autor ao propor "a primeira tentativa radical de diferenciar dois tipos bem definidos de mulheres - um positivo e outro negativo", partindo, para tanto, da análise dos efeitos da guerra sobre as mulheres: o desenvolvimento de características psicológicas masculinas, a expansão do público 
leitor feminino e o aumento do ímpeto de confronto com os homens. A seu ver, todos esses elementos poderiam ser tomados como positivos, o que dependeria da atitude mental das mulheres diante da vida, ou seja, desde que isso não significasse a subversão das mulheres em relação ao único poder, a "mão de ferro" que as poderia governar: o poder do homem (Idem, ibidem).

Em seu comentário ao livro, Gramsci afirmou que o feminismo deveria ser estudado em "suas causas mais vastas e profundas", e não tomado simplesmente como movimento de pessoas desqualificadas surgido em um contexto de questionamento da classe política (e 1, \$146, p. 130). Em maio de 1930, no último parágrafo do Quaderno 1, \$158, Gramsci voltou ao tema das crises "sexuais” geradas pelas mudanças provocadas pela guerra e pelo industrialismo. “Toda época histórica possui uma”, afirmou, sentida especialmente pelas classes médias, mas que "não toca senão superficialmente as massas trabalhadoras ou as toca sentimentalmente porque deprava suas mulheres" ( $\mathrm{Q} 1, \$ 158$, p. 138, grifo adicionado) devido ao fator ideológico iluminista difundido pelas classes não manualmente produtivas:

\footnotetext{
O pós-guerra teve uma crise similar, talvez a mais vasta já vista na história; mas a pressão era exercida não para impor uma nova forma de trabalho, mas pela necessidade da guerra. A vida de trincheira foi objeto principal da pressão. Foram desencadeados principalmente os instintos sexuais, reprimidos por tantos anos nas grandes massas de jovens dos dois sexos e que adquiriram aspecto formidável pelo desaparecimento de tantos homens e por um equilíbrio entre os sexos (Idem, p. 138).
}

Essa crise era especialmente mais forte dado o contraste entre os efeitos "libertários" da guerra e a necessidade de disciplinarização para os novos métodos industriais de trabalho. Enquanto aqueles destruíam os laços tradicionais, esses exigiam um reforço da "família" em sentido amplo para "regulação e estabilidade das relações sexuais". Essa crise paradoxal, continuava, ganhava contornos ainda mais dramáticos "em um estado onde as classes trabalhadoras não sofrem mais a pressão violenta de uma outra classe" e "a nova atitude de trabalho deve ser adquirida apenas por via da persuasão e do convencimento" (Idem, p. 139). Nesse caso - a referência era a sociedade soviética - emergia "uma situação ambígua entre a ideologia 'verbal' que reconhece as novas necessidades e a prática 'animalesca' que impede aos corpos físicos de realmente adquirirem os novos hábitos" (Idem, ibidem). Em outras palavras, surgia "uma situação de grande hipocrisia social totalitária", já que não se tratava mais de uma "hipocrisia de classe" (Idem, ibidem). Assim, concluía, "é uma crise 'em permanência' que apenas a coerção pode confrontar, uma coerção de novo tipo já que, sendo uma classe apenas, será autodisciplina" (Idem, ibidem). 
Em parágrafo escrito pouco depois, entre julho e agosto de 1930, no Quaderno 3, $\$ 61$, Gramsci voltou ao tema dos conflitos "sentimentais" gerados pela crise, tratados como "lutas de gerações": "o fato de que a geração antiga não possa guiar as gerações mais jovens é, em parte, expressão da crise da família e da nova situação do elemento feminino na sociedade" (Q $3, \$ 61$, p. 340, grifo nosso). Essas mudanças rápidas e profundas, contudo, determinavam "um empobrecimento 'sentimental' com relação ao passado e uma mecanização da vida" (Idem, ibidem). Isso acarretaria a renúncia pela "geração antiga" em cumprir a "tarefa educativa" das mais jovens, em "determiná-las", substituindo um princípio educativo vigoroso por "formas de estatolatria". A crise do sentimento se referia, aqui, a uma transformação profunda e tumultuada da "consciência" vivida, do passado e do futuro pelos indivíduos. Paradoxalmente, concluía Gramsci, sob um princípio educativo estatólatra, os indivíduos passavam a confundir Estado e burocracia estatal, ou seja, passavam a negar o elemento estatal contido em si mesmos, "elemento social homogêneo", "ativo na vida social", aderente e elaborador inteligente de um programa que governa (Ibidem). A nova condição feminina era a ponte que o levava a pensar os dilemas de uma independência social que não poderia realizar-se no (e como) Estado sem ser uma nova condição humana.

Já nos primeiros meses de escrita dos Quaderni del carcere, portanto, a "questão sexual" não poderia ser tomada como algo exterior, um processo de ajuste - planejado ou espontâneo - às necessidades do "mundo econômico" em formação; sendo a "função reprodutiva" uma questão fundamentalmente política, deveria ligar-se centralmente aos desafios da conquista da independência das mulheres. A partir dessa aproximação sobre a questão feminina nos escritos carcerários, duas questões são pertinentes para o presente artigo. A primeira: quais as possíveis origens dessa formulação sobre a importância política da questão feminina em Gramsci? A segunda é: como esse assunto se desenvolveu nos Quaderni ao longo do tempo?

\section{O movimento socialista e o crumiraggio feminino}

A atividade política e o movimento de mulheres na Itália possuem uma trajetória que remonta à sua participação nas lutas de unificação nacional no século XIX e, desde então, na construção ativa de associações, partidos políticos, sindicatos (Bortolotti, 1963). Na virada do século XIX-xx, inclusive, essa atividade possuía características bem delimitadas, particularmente no ambiente socialista italiano em que despontavam lideranças como Anna Maria Mozzoni, Anna Kuliscioff, Maria Giudice, Angelica Balabanoff etc. No final do século XIX, contexto do nascimento daquele que viria a ser o Partido Socialista Italiano, a questão feminina já acumulava algumas décadas de reflexão sob forte recepção "das doutrinas iluministas de Fourier 
e pelas ideias de John Stuart Mill” sobre sujeição e autonomia das mulheres (Alloisio e Ajó, 1978, p. 3).

A característica particular que essa questão assumiu no movimento socialista nesse momento se vinculava aos esforços de elaboração de uma "lei sobre o trabalho das mulheres" (Idem, p. 8). Esta não era, contudo, uma questão consensual e boa parte do debate entre as mulheres socialistas na virada do século girava em torno da “inferioridade" e "tutela” feminina em relação aos homens que as leis de regulação do trabalho pressupunham ou impunham (Idem, pp. 10-11). Nesse sentido, não eram debates muito diferentes daqueles enfrentados por mulheres em toda a Europa no mesmo período, em especial o confronto com um forte e misógino corporativismo sindical que via no trabalho feminino fundamentalmente uma ameaça, tanto ao trabalho assalariado masculino como à estrutura e dinâmica familiar patriarcal (Goldman, 2014).

Foi no Congresso do Partido Socialista Italiano realizado em 1911, em Modena, que pela primeira vez se afirma a exigência de diferenciação de um feminismo "classista” em relação ao feminismo burguês (Alloisio e Ajó, 1978, p. 20). Também nesse congresso se discutiu a necessidade do partido de dar mais atenção às lutas femininas pelo sufrágio, nos sindicatos etc. No congresso do ano seguinte, realizado na Reggio Emilia, por sua vez, é fundada a União Feminina Socialista [Unione Femminile Socialista] e o periódico A Defesa das Trabalhadoras [La Difesa delle Lavoratrici], ${ }^{3}$ o mais importante jornal feminista e socialista da época. O primeiro número, publicado em janeiro de 1912, enviado gratuitamente aos assinantes do jornal socialista Avanti!, trazia impresso um curioso anúncio para estimular as assinaturas, que dizia:

Lembre, companheiro, que se a mulher não é sua aliada e ajuda na luta contra o capitalismo será, por força das coisas, a sua pior inimiga e o obstáculo insuperável na batalha: inimiga na vida pública, na qual seu krumiraggio enfraquecerá o nervo da sua resistência e contribuirá a diminuir os salários; inimiga no ambiente doméstico, onde hostilizará a tua ação no partido e nas organizações (La Difesa delle Lavoratrici, 1912, a. 1, n. 2, p. 1).

Krumiraggio ou crumiraggio era um termo pejorativo usado no jargão sindical italiano desde o início do século xx para se referir ao abstencionismo ou mesmo boicote às atividades sindicais, bem como designava os trabalhadores não especializados mobilizados para substituir grevistas. De origem francesa ${ }^{4}$, contudo, era também uma

3. Periódico fundado por Anna Kuliscioff, Linda Malnati, Margherita G. Sarfatti, Carlotta Clerici e Giselda Brebbia, editado em Milão e de início publicado quinzenalmente. Foi publicado até setembro de 1925.

4. Em francês, o termo de conotação racial Kroumirs, por sua vez, se refere aos habitantes da Crumíria, na região na Tunísia, que no século XIX se notabilizou no contexto dos diversos conflitos na fronteira com 
forma popular de conotação racista usada para identificar os trabalhadores imigrantes, especialmente os vindos do Norte da África (Orioles, 2002). Do ponto de vista socialista, portanto, a educação e a organização política dos interesses femininos correspondiam a uma necessidade imediata de evitar potenciais "obstáculos" nas dinâmicas sindical e partidária estabelecidas devido a sua condição política "atrasada", tal como aqueles postos pelos trabalhadores de baixa qualificação e imigrantes que aceitavam ocupar o posto de outros durante as greves.

Em 20 de janeiro, Clara Zetkin - então Secretária da União Internacional das Mulheres Socialistas - publicou artigo de saudação ao novo periódico, destacando a importância internacional de um jornal voltado para as mulheres operárias italianas no momento em que "as necessidades da vida não permitem mais às mulheres do povo permanecerem estranhas à vida e lutas da política” (Zetkin, 1912, p. 2). O aumento da participação política das mulheres proletárias, particularmente das “mães”, fortaleceria a reação a uma ameaça internacional imediata: o ascenso do militarismo nos diversos países da Europa. Zetkin via na organização das mulheres um instrumento para enfrentar o imperialismo, "a aspiração a sempre novas colônias [que] conduz a requerer sempre novos filhos do povo nas casernas" (Idem, ibidem). De maneira geral nesse contexto, a "defesa das trabalhadoras" era pensada como mobilização auxiliar às lutas socialistas e operárias já em andamento; isso explicava e justificava tanto seu classismo como a oposição ao "feminismo burguês".

A guerra iniciada em 1914 levaria essa perspectiva a uma situação paradoxal. Por um lado, ampliou drasticamente a participação das mulheres na atividade industrial italiana, desequilibrando a relação entre homens e mulheres na composição social e produtiva dos países envolvidos (Alloisio e Ajó, 1978, p. 45). Por outro, projetou sobre as mulheres socialistas um papel político em nada "complementar" às lutas sindicais e parlamentares do período anterior: de luta pelo fim da guerra e pela paz. O protagonismo feminino durante o conflito bélico se expressou fortemente em termos internacionais, com a realização em 1915 de um Congresso Internacional de Mulheres Socialistas em Berna que, depois do conflito, se converteria em uma rede internacional de organização de mulheres em solidariedade à Revolução Russa liderada por mulheres como Zetkin, Inessa Armand, Alexandra Kollontai, Nadeja Krupskaia, entre outras.

Também no ambiente italiano o protagonismo feminino foi notável nos embates dos direitos trabalhistas e contra a guerra. Em agosto de 1917, Maria Giudice - colunista de $A$ Defesa das Mulheres Trabalhadoras e editora-chefe do jornal socialista $O$

a Argélia que culminaram com a invasão francesa da Tunísia. Disponível em: http://www.treccani.it/ vocabolario/crumiro. 
Grito do Povo [Il Grido del Popolo] - foi presa ao liderar uma importante manifestação contra guerra pelas ruas de Turim. Em seu lugar, Antonio Gramsci assumiria a direção do jornal da capital do Piemonte até seu fechamento. Também em Turim atuava nesse período Camilla Ravera ${ }^{5}$, dirigente socialista (e posteriormente comunista) próxima a Gramsci, de quem receberia a incumbência de organizar, em fevereiro de 1921, a coluna semanal "Tribuna das Mulheres" [Tribuna delle Donne], dedicada à “emancipação feminina”, no agora cotidiano comunista $A$ Nova Ordem [L'Ordine Nuovo] (Ravera, 1973, p. 97).

Nos escritos de Gramsci desse período não é possível mapear uma preocupação específica com a questão feminina. $\mathrm{O}$ que se aproximava mais disso era a reflexão sobre a família, como em um artigo de fevereiro de 1918 publicado em $O$ Grito do Povo (então dirigido por Giudice). Neste, a família era apresentada como “organismo moral", o "primeiro núcleo social que supera o indivíduo", impondo a ele obrigações e responsabilidades ( $\mathrm{CF}, 647)$. No regime socialista, continuava, a família subsistiria como forma de proteger as crianças das "instituições do Estado, impessoais, mecânicas e burocráticas" (Idem, pp. 647-648).

No início de 1920, Gramsci comentou em diferentes artigos a intervenção parlamentar de Filippo Turati a respeito do "voto feminino e as assalariadas do amor", que se tornara muito popular no movimento de mulheres socialistas. Realizado a 4 de setembro de 1919 e publicado em três partes entre outubro e novembro no $A D e$ fesa das Trabalhadoras com o título de "Il voto della donna e le salariate dell'amore", o discurso de Turati (1919a; 1919b; 1919c) discutiu a reforma eleitoral que em agosto de 1919 garantiu a expansão do sufrágio aos ex-combatentes da guerra e o sistema de representação proporcional, este último aprovado sob pressão socialista. O voto feminino, contudo, ficara de fora da reforma ${ }^{6}$.

Em seu discurso, Turati discutiu a reforma eleitoral confrontando o argumento conservador da "incapacidade" das mulheres para votar e afirmando que na sociedade italiana as mulheres já se haviam “tornado homens”, ou seja, já poderiam ser consideradas cidadãs. Polemizou, ainda, contra o argumento de que a prostituição assinalaria a incapacidade feminina para o voto por ser uma conduta sexual incorreta (Turati, 1919a, p. 2). Comparou, para tanto, a prostituição com a prática da

5. As memórias de Ravera nos anos de convivência com Gramsci possuem valor imprescindível para a reconstrução do pensamento gramsciano nesse período (Ravera, 1973). Para uma interpretação da relação de Gramsci e a participação das mulheres trabalhadoras na política em Turim tomando como base as memórias de Ravera, ver Donno, 2008, pp. 121 ss.

6. Em 1925, já como deputado, Gramsci votaria contra um projeto de reforma eleitoral fascista que mantinha a exclusão do voto feminino das eleições políticas e dos analfabetos do sufrágio político e administrativo (Bartolotti, 1977, p. 540). O voto feminino só seria conquistado plenamente na Itália depois da Segunda Guerra Mundial, em 1946. 
corrupção e a hipocrisia da classe política italiana, afirmando que as "assalariadas do amor" poderiam ser tomadas por prestadoras de um serviço público e, por isso, mais honestas que a classe política (Idem, 1919b; 1919c).

Gramsci comentou esse discurso em dois artigos de L'Ordine Nuovo publicados em 7 e 20 de fevereiro de 1920. No primeiro, intitulado "O Estado italiano" [Lo Stato Italiano], falou que Turati substituía a reflexão sobre o massacre de 15 milhões de pessoas em cinco anos de guerra por um "elegante discurso sobre o direito ao voto das prostitutas", o que evidenciava a "nulidade oportunista e reformista" que passara a dominar a direção do Partido Socialista Italiano (PSI) (ON, p. 282). Em um contexto de afirmação da "república dos sovietes" e da "democracia operária”, Turati optava pela "república burguesa" e a "democracia liberal" (Idem, ibidem). Em seguida, no artigo "O instrumento de trabalho" [Lo strumento di lavoro], voltou a se referir aos "reformistas e oportunistas" como aqueles que "nunca estudaram os problemas reais da classe operária e do socialismo", distantes de “todo contato físico e espiritual com as massas proletárias e a realidade histórica” (Idem, p. 289). Para Gramsci, o uso que Turati fazia da retórica sobre o voto feminino revelava a preferência do líder socialista pela "intriga parlamentar" diante da realidade das classes trabalhadoras no pós-guerra, das greves operárias e dos conselhos de fábrica que se organizavam entre 1919 e 1920, em uma postura condescendente com a expansão mórbida do Estado italiano no pós-guerra gerada pelo crescimento da burocracia, do policiamento e de organismos parasitários nas instituições estatais (Idem, p. 290).

No início de 1921, contexto da cisão com o PSI e fundação do Partido Comunista na Itália, Camilla Ravera relatou em suas memórias os esforços por organizar um movimento de mulheres "não feminista", ou seja, não socialista mas inserido "no quadro mais geral da emancipação proletária”, voltado para o problema de assegurar trabalho e salário iguais às mulheres da classe trabalhadora (Ravera, 1973, pp. 97-98). Relembrou, ainda, a participação de Gramsci na primeira reunião de mulheres comunistas, realizada em meados de 1921 em Roma, e o uso, no discurso desse, de ideias de Lenin sobre o papel das mulheres na revolução socialista (Idem, pp. 112-113). Dessa conferência, Gramsci escreveu:

Um número exíguo de companheiras interveio na conferência [...] a discussão se desenvolveu de modo um pouco fragmentário e vago, mesmo confuso; e a confusão foi produzida ou agravada por preocupações e colocações de caráter feminista (apud Ravera, 1973, p. 114).

Para Gramsci, então, o modo comunista de colocar o problema das mulheres deveria ser a realização de sua "independência econômica", reconhecendo nas "funções particulares e ocupações" femininas, como a maternidade, o cuidado com as 
crianças e a casa, "o valor de uma função e de uma produção social" (Idem, p. 114). Além disso, apostava na "industrialização do trabalho doméstico" como o caminho para a "libertação das mulheres da escravidão doméstica", com impacto grande e imprevisível sobre a "moral" e o costume" de toda a sociedade (Idem, ibidem).

\section{A questão feminina pós-revolução}

Desde 26 de maio de 1922, Gramsci estava fora da Itália. Viajou inicialmente para Moscou para participar de alguns encontros importantes de organismos dirigentes da Internacional Comunista (IC), particularmente das reuniões do Presidium e do Plenum - o qual passou a compor o órgão executivo. Em meados de julho desse ano, contudo, começou a sofrer crises de saúde, possivelmente nervosas (E, p. 254n), que o levaram a intercalar suas atividades como dirigente a períodos de descanso em um sanatório em Serebrjanij Bor, próximo a Moscou, onde conheceu as irmãs Eugenia e Giulia Schucht e se aproximou delas - com Giulia ele viria a ter dois filhos. Com base na correspondência do dirigente comunista italiano Amadeo Bordiga com representantes da IC nesse mês, é possível saber que Gramsci se hospedava muito próximo de Clara Zetkin em Moscou (E, p. 206n)7 . Zetkin compunha, além disso, a comissão internacional indicada para pensar a "questão italiana", tema sobre o qual a dirigente alemã já escrevera no III Congresso da Internacional Comunista (realizado em 1921), assim como sobre a "questão feminina" e o movimento de mulheres comunistas.

Assim, os meses que separaram a chegada de Gramsci à Rússia, no início de junho de 1922, e a participação no encontro do Presidium sobre a questão italiana, realizado em 29 de setembro do mesmo ano, revelam um importante entroncamento biográfico: as crises nervosas que o impediram de exercer plenamente as atividades como dirigente partidário, o contato pessoal e afetivo com as irmãs Schucht e a possível interlocução com Zetkin a respeito de temas como a questão feminina e o emergente fascismo italiano. Como pano de fundo desse entroncamento, por sua vez, estava a difícil interlocução entre Gramsci, a delegação comunista italiana e a direção da IC a respeito da estratégia política a ser adotada na Itália (Rosengarten, 1984-1985).

Há alguns anos, Zetkin enfrentava o desafio da organização das mulheres comunistas na Alemanha. Em suas lembranças de conversas com V. I. Lenin - texto preparado para publicação depois da morte do dirigente russo, entre janeiro de $1924 \mathrm{e}$ janeiro de 1925, a partir de anotações de 1920-1921 -, a consciência das dificuldades dessa construção é explícita (Zetkin, 1929). Zetkin relata, por exemplo, uma longa

7. Para um relato de Ravera sobre a concordância de Gramsci com as posições pela "emancipação feminina" no movimento comunista, ver Camparini (1991). 
conversa com Lenin - realizada provavelmente em junho de 1921, no contexto da preparação do III Congresso da IC - a respeito dos impasses do desenvolvimento do movimento de mulheres na Europa.

Lenin reconhecia a "grande importância do movimento de mulheres como parte essencial, em certas circunstâncias decisiva, do movimento de massas” e a necessidade de "criar um poderoso movimento internacional de mulheres sobre uma clara base teórica" que permitisse a distinção entre a política comunista e a dos demais partidos (apud Zetkin, 1929, p. 47). Em 1903 é possível encontrar em seus escritos a defesa da "completa igualdade de direitos entre homens e mulheres"; em 1913, a crítica à hipocrisia burguesa no tratamento público repressivo e moralizante da prostituição; em 1915, a defesa do "ponto de vista proletário" no movimento de mulheres; em 1919, a polêmica contra o "neomalthusianismo" dos intelectuais burgueses que defendiam o controle de natalidade entre as camadas populares como forma de "evitar a ruína” (Lenin, 1969, pp. 7-8, 29-30, 39). Em 1920-1921, essa reflexão aparece na discussão com Zetkin como necessidade de defender o pioneirismo da "igualdade social para as mulheres" finalmente conquistada pela "primeira ditadura proletária" (Lenin apud Zetkin, 1929, pp. 48-49).

Lenin reconhecia, contudo, que essa "distinção" era uma construção difícil de realizar pois o movimento de mulheres europeu, fortemente influenciado pelas culturas socialista e liberal-democrática, mantinha-se excessivamente afastado da nova realidade. As críticas de Lenin avançavam, além disso, sobre as "teorias sexuais" que se difundiam na Europa desde a virada do século XIX-XX, inclusive no ambiente comunista, particularmente a "teoria freudiana”. Apesar da aparência "erudita” e até "científica", afirmou, essas teorias floresciam "no solo imundo da sociedade burguesa" e, com suas hipóteses arbitrárias, serviam, antes de mais nada, para "justificar” as "anormalidades e hipertrofia sexual" produzidas pela sociedade burguesa diante de sua moral (Idem, p. 52) ${ }^{8}$.

Essa percepção levou Lenin a criticar a atuação de Zetkin e da organização das mulheres alemãs, usando como exemplo a iniciativa de organização de prostitutas no partido comunista na cidade de Hamburgo (Idem, p. 50) ${ }^{9}$. Apesar de reconhecer o mérito político da defesa de mulheres "duplamente sacrificadas pela sociedade burguesa", "pelo sistema de propriedade e pela hipocrisia moral", Lenin questionou a centralidade dessa atuação específica em um contexto em que "os sovietes ainda estão na agenda política dos alemães” (Idem, ibidem). Não pensar a organização

8. O ambiente comunista era crítico - e mesmo refratário - à questão feminina, e isso influenciou em certa medida as análises de Gramsci sobre o tema antes da prisão (Mancina, 1987).

9. Para uma interpretação crítica da posição de Lenin e dos bolcheviques sobre este tema, ver Landes (1981) e Honeycut (1981). 
política com base na nova correlação de forças aberta pela revolução de 1917 levaria, a seu ver, a uma corrupção e degeneração do próprio mérito dessa atuação, já que reconduzia a questão feminina necessariamente aos limites burgueses da política reformista e oportunista do período anterior (Idem, p. 51). Mesmo na Rússia soviética, reconhecia, essa era uma questão que levantava problemas de difícil solução: como aproximar as prostitutas do trabalho produtivo e da economia social, especialmente em um cenário de forte crise econômica e fome? (Mussi, 2017). A situação na Alemanha, por sua vez, exigia a maior "concentração possível de todos os proletários", o que não poderia ser alcançado se as mulheres trabalhadoras passassem a discutir prioritariamente "problemas sexuais e questões das formas de casamento no passado, presente e futuro" (Lenin apud Zetkin, 1929, pp. 51-52).

Em sua defesa, Zetkin afirmou que as "questões de sexo e casamento em uma sociedade burguesa de propriedade privada envolvem muitos problemas, conflitos e muito sofrimento para as mulheres de todas as classes e níveis" e que se acentuaram enormemente depois da guerra (Idem, p. 53). Paradoxalmente, os efeitos da guerra e da revolução sobre os "assuntos sexuais" trouxeram à tona problemas antes "escondidos" das mulheres a respeito das formas assumidas pelo casamento e pela família. Percebidas agora como frutos do desenvolvimento histórico e da vida econômica, essas formas perdiam a aparência de "eternidade", o que levava as mulheres à descoberta e condenação da hipocrisia moral burguesa (Idem, ibidem). Por isso, concluía, esses temas eram tão importantes para elas, apesar de superficialmente aparentarem mais uma reconexão com a política reformista tradicional.

Apesar das divergências quanto ao "ritmo" da construção do movimento de mulheres na Alemanha, Zetkin e Lenin concordavam que a construção da política comunista passava por entender a complexidade das "superestruturas" cultural e ideológica dos diferentes países europeus, além da base econômica (Idem, p. 57). Esse problema, aliás, conduziu boa parte dos debates da IC no início dos anos 1920 a respeito dos dilemas da expansão da revolução no continente europeu. Para Lenin, além disso, o problema passava necessariamente pelo desenvolvimento de formas contundentes de autocontrole e autodisciplina pelos comunistas e pelas massas soviéticas, o que necessariamente o levava a uma atitude crítica frente às teorias sobre liberação sexual correntes na época.

Apesar dessas discussões e dos debates no interior da IC sobre o movimento de mulheres, além das iniciativas de propaganda entre mulheres impulsionadas pelo L'Ordine Nuovo em Turim, os escritos de Gramsci como dirigente político até a prisão em 1926 não discutem especificamente a questão feminina ${ }^{10}$. O foco está

10. Para uma apreciação dos primeiros esforços do PCI em uma atividade de propaganda entre as mulheres 
em reorientar a organização da política comunista no país no contexto de escalada do fascismo como regime político autoritário no país. Apesar disso, no conhecido discurso parlamentar, de 23 de maio de 1925, sobre as "Origens e objetivos da lei sobre as associações secretas" [Origini e scopi della legge sulle associazioni segrete], Gramsci mencionou as mulheres. No discurso, elencou as três principais debilidades da burguesia italiana antes da guerra e, por continuidade, do fascismo: a dificuldade de enraizar a indústria no país, a ausência de colônias ligadas à pátria-mãe que permitissem o surgimento de uma aristocracia operária forte e, por fim, a questão camponesa, "ligada estreitamente ao problema da imigração" ou a incapacidade da burguesia em manter os trabalhadores no país (CPC, p. 78). A imigração, emendou,

[...] afasta do território nacional uma tal massa de população masculina, economicamente ativa, que as relações demográficas se tornam catastróficas [...] no território nacional permanecem os velhos, as mulheres, crianças, inválidos, ou seja, a parte passiva da população. (Idem, ibidem, grifos nossos).

As mulheres apareciam associadas aos contraefeitos do processo migratório (como antes já haviam sido no contexto do conflito bélico e do recrutamento militar), ou seja, compunham o setor fundamentalmente passivo dos que "permaneciam" no país. Se, no contexto da guerra, o bloco formado entre o governo de Giovanni Giolitti ${ }^{11} \mathrm{e}$ os socialistas cumprira o papel de dividir a classe trabalhadora e "oprimir a massa dos camponeses italianos", especialmente na região meridional, o fascismo atuava agora não para solucionar o problema, mas para "nivelar na mesma miséria” aristocracia operária e camponeses pobres em todo o país (Idem, p. 79). Em outras palavras, atuava para ampliar o setor passivo - improdutivo, desagregado e desorganizado - da sociedade italiana. Gramsci retornou ao problema da imigração no ano seguinte, em um manuscrito de poucos meses antes de sua prisão em novembro de 1926 (Idem, pp. 137 ss.). Neste, destacou como aspecto central da política socialista e posteriormente comunista em Turim a sensibilidade com a "questão meridional", os esforços por desconstruir os sensos comuns sobre o "atraso", "preguiça”, "incapacidade" e "barbarismo" dos camponeses do Sul da Itália (Idem, p. 140). A política comunista em Turim, concluiu, se distinguia por confrontar uma ideologia que impedia "a criação

nos anos 1920, bem como para a influência dos escritos de Lenin sobre o tema, ver Gabrielli (1989). Para os debates específicos sobre a condição feminina na coluna do jornal L'Ordine Nuovo, "Tribuna della Donna”, assinada por Ravera e a publicação quinzenal de mesma finalidade, Compagna, ver Slaughter (2011, pp. 266 ss.).

11. Giovanni Giolitti foi um político liberal italiano, presidente do Conselho de Ministros em cinco diferentes mandatos entre 1892 e 1921. 
de um sistema de alianças de classes que permita mobilizar contra o capitalismo e o Estado burguês a maioria da população trabalhadora" (Idem, ibidem).

Não existem registros anteriores ao período do cárcere em que Gramsci tenha discutido ou afirmado a importância da "salvaguarda da personalidade feminina", apesar dos indícios de que tenha tomado contato com o tema e mesmo com as posições de Lenin sobre o assunto no período em que viveu em Moscou, em 1922, por meio da convivência com Zetkin e do contato com a experiência soviética. Os escritos pré-carcerários, aliás, apontam para uma atitude crítica de Gramsci em relação à abordagem socialista do movimento de mulheres, a qual via como expressão de uma prática política oportunista e reformista, de contornos democrático-liberais. A ausência de qualquer referência ao tema e/ou de um plano para organização de mulheres nas Teses de Lyon, escritas por Gramsci e Palmiro Togliatti, em janeiro de 1926, para orientar o partido comunista parece confirmar a hipótese de que a "questão feminina" não era considerada um problema especificamente relevante (Idem, pp. 488-513).

Um prisioneiro em busca de uma "mulher viva"

Salta aos olhos a originalidade dos escritos do período carcerário a respeito da questão feminina, do feminismo e da relação entre a condição da mulher e a condição de classe. Aqui, esses temas aparecem vinculados, por um lado, ao problema do impacto da imigração e da guerra nas relações sexuais - nesse sentido, são desdobramentos de análises anteriores -, mas contêm uma novidade que só é possível compreender levando em conta a experiência de Gramsci na prisão e as trocas de cartas pessoais sobre a saúde da esposa e a criação dos filhos ${ }^{12}$. Nas cartas trocadas entre 1927 e 1928 com Giulia, Gramsci insiste em ter notícias da família (LC, p. 131, 137) e fala de suas "crises de resistência ao novo modo de viver" como prisioneiro (Idem, p. 163), do sentimento de apatia e inércia que dificulta a "estabilização da vida" no cárcere (Idem, p. 221). Contudo, a partir de março de 1929 - contexto em que Gramsci começou a preencher seus "cadernos" -, as crises depressivas de Giulia, suas causas e tratamentos, passam a ganhar relevância na correspondência (Idem, p. 244) ${ }^{13}$.

$\mathrm{Na}$ correspondência com a mulher - que desde meados de 1926 passara a morar em Moscou com os dois filhos pequenos - as crises depressivas dessa passaram a ser tema recorrente. "Pelas fotos parece que você não esteve bem", Gramsci escreveu a

12. Em agosto de 1926, Giulia regressara a Moscou com o filho Delio, então com dois anos, e estava grávida de Giuliano. Gramsci nunca voltaria a rever a família ou a conhecer pessoalmente o filho mais novo (Fiori, 2003, pp. 240-241).

13. Para uma leitura diversa da relação entre Gramsci e Giulia, ver Chataway (1995). 
Giulia, em março de 1929, "espero que me envie mais detalhes da tua saúde” (Idem, ibidem). Poucos meses depois, no final de julho, escreveu à Giulia sobre as "vezes [que] pensei em escrever sobre você, sobre a sua força, que é cem vezes superior ao que você imagina, mas sempre hesitei porque isso me parece... um senhor de escravos [negriero] que acaricia uma besta de trabalho" (Idem, p. 277). "Não deveria pensar assim", continuou, mas "sobrevivem ainda hoje em mim, como sentimentos reprimidos, muitas concepções ultrapassadas, superadas criticamente porém não completamente abolidas" (Ibidem). Gramsci entendia que Giulia, “objetivamente”, suportava "os pesos mais duros" da relação dos dois, o que exigia dela um esforço contínuo e extenuante.

Em janeiro de 1930, falou em carta à cunhada Tatiana sobre a dificuldade de lidar com o afastamento de Giulia devido à falta de correspondência - "pode Giulia ser para mim 'ambiente externo'”? (Idem, pp. 306-307) - e sobre a vontade de oferecer "um pouco de força" para a mulher "lutar contra [...] os pesos esmagadores da nossa união" (Idem, p. 307). Alguns meses mais tarde, em 5 de maio, escreveu à Giulia preocupado com "seu estado de ânimo e condições de saúde" e sobre a decisão desta em esconder informações sobre sua condição. Em meados de julho, voltou ao tema da "contabilidade epistolar" entre os dois, evidenciando que entre julho de 1920 e julho de 1930 Giulia não havia escrito sequer uma carta (Idem, p. 343). Ao analisar as fotografias que recebera da mulher e dos filhos por intermédio da cunhada, tinha a impressão de que Giulia atravessava uma "crise grave”, dada sua expressão "doce e suave" combinada a "algo novo, não sei se dolorido ou resignado" (Idem, ibidem). Estou convencido, concluiu, "que você ignora a si mesma e as reservas de energia que possui, as crises de fraqueza e depressão se devem a isso" (Idem, p. 344).

No início de outubro, falou em carta sobre a dificuldade de estabelecer, com Giulia, uma correspondência com um diálogo efetivo e não uma "série de monólogos" (Idem, p. 358). Em seguida, teve acesso por meio de Tatiana ao relato do amigo Piero Sraffa, que visitara a família de Gramsci em Moscou e pôde constatar que as condições de saúde de Giulia não eram boas (Idem, p. 843). A Sraffa, Giulia confidenciou que escondia do marido o verdadeiro estado de saúde e, consequentemente, se via diante da impossibilidade de escrever francamente sobre si mesma (Idem, ibidem). Em 4 de novembro, Gramsci escreveu a Giulia para dizer que "tudo foi descoberto", "não existem mais mistérios para mim", "fui detalhadamente informado sobre seu estado de saúde" (Idem, pp. 362-363). Alguns meses mais tarde, em janeiro de 1931, voltou ao tema novamente em carta à Giulia para falar sobre sua experiência como prisioneiro e para dizer que, ao escrever para ele, ela deveria antes de mais nada escrever "para si mesma”, afinal, "me parece que você também está isolada e um pouco fora da vida, escrevendo pode sentir um pouco menos essa íntima solidão” (Idem, 
p. 385). Em carta de 9 de fevereiro, contudo, pareceu se dar conta de que havia algo que até então não entendera bem:

Uma vez escrevi (talvez você lembre) que estava convencido que você sempre fora mais forte do que seria capaz de reconhecer, mas que me repugnava insistir sobre isso porque me parecia uma atitude de senhor de escravos, dado que sobre você recaem os pesos grandes da nossa união. Penso assim ainda hoje mas isso não significa que faço de você a imagem de uma "mulher forte", de maneira convencional e abstrata: sabia que você estava fraca, muito fraca, que era, em resumo, uma mulher viva, que era a Julka (Idem, p. 391, grifo nosso).

"Pensei muito sobre essas coisas desde que estou na prisão", continuou, e "me convenci que sobre sua fraqueza e força cometi muitas bobagens" (Idem, ibidem). Para Gramsci, ficava claro que o "figurino” de mulher forte criado para Giulia ajudava a inibir sua escrita, fenômeno contra o qual ela lutava sem sucesso. "Me ajude e me ensine o modo melhor de ajudá-la”, avançou Gramsci, “orientando sua vontade”, "desfazendo qualquer falsa representação" do passado e "me ajudando a conhecer melhor os meninos e participar da sua vida", ou seja, a conquistar a "paternidade viva”, não um fato do passado cada vez mais distante (Idem, pp. 392-393).

Ao longo desse ano, é possível notar o desdobramento do que Gramsci notava, agora, em sua correspondência com Giulia: esta não deveria ser estabelecida apenas como "fato quantitativo", sistemático, mas dependeria sobretudo da conformação de "uma nova personalidade qualitativa” (Idem, p. 394), que pudesse superar a "aceitação [por Giulia] de uma função subalterna nas decisões” (Idem, pp. 453-454). Além disso, percebia que socialmente a "função subalterna" era muito mais numerosa e diversificada do que poderia parecer, que conformava um verdadeiro exército de "pessoas presas nos contrastes férreos da vida moderna”, nas dificuldades em conseguir com meios próprios "pensar os contrastes e superá-los, alcançando uma nova serenidade e tranquilidade moral” (Idem, p. 532). Em todo caso, em janeiro de 1933 Gramsci seguia considerando Giulia “a melhor terapeuta” para si própria, alguém "mais forte do que pensa e que deve ter firmeza e integridade para superar de maneira decisiva a crise que enfrentou" (Idem, p. 674) e sair da posição subalterna, de quem "não está em condições de criticar historicamente as ideologias, dominando-as, explicando-as, justificando-as como uma necessidade histórica do passado" (Idem, p. 736). Até janeiro de 1937 e as últimas cartas trocadas entre os dois, a "centralidade" de Giulia permanece, "elemento essencial” da vida de Gramsci, inclusive nos silêncios (Idem, p. 766). Em janeiro de 1937, poucos meses antes de morrer, Gramsci falou da importância das cartas de Giulia, as quais "relia muitas vezes", a primeira vez "desinteressadamente" e depois "criticamente", buscando identificar "como você 
estava quando escreveu”, observando "a escrita", "a firmeza maior ou menor das mãos", "todas as indicações e significados possíveis" (Idem, p. 795).

Uma nova mulher, uma nova ética

Na segunda metade de 1934, fase avançada de seus escritos na prisão, Gramsci redigiu o conhecido caderno especial dedicado ao tema do "Americanismo e fordismo". Neste, anunciou logo no primeiro parágrafo um conjunto de problemas a serem estudados como "anéis em uma cadeia" para compreender as diferentes formas de resistência das "forças subalternas" ao processo histórico, imanente, de "organização de uma economia programada" Q 22, \$1 (p. 2140). Neste, a "questão sexual” apareceu em segundo lugar. Ao longo do parágrafo seguinte, o Quaderno 22 incorporou com maiores ou menores modificações o que Gramsci havia escrito no início de 1930 sobre a questão sexual e feminina ( $\mathrm{Q} 1, \$ \$ 61,62,146,158)$.

O parágrafo Q 22, $\$ 2$ desenvolveu o conteúdo do Q 1 , $\$ 61$ sobre “Americanismo" e, na passagem sobre a ausência de mulheres em ocupações produtivas como uma das origens da "insalubridade" da composição demográfica italiana, completou a frase "trabalhos produtivos de novos bens" (Q 22, 2 , p. 2144, grifo adicionado). Dessa maneira, destacou, por um lado, a importância política de um setor econômico específico e, por outro, afastou a ideia de que as mulheres estariam fora de qualquer atividade econômica produtiva. No parágrafo seguinte, Q22, §3, Gramsci fez o mesmo do Q $1, \$ 62$, com algumas alterações importantes. Na passagem sobre a sexualidade como função reprodutiva e como "esporte" no campo e na cidade, incluiu o pressuposto de que esta última se difundia também "nas relações sexuais entre os elementos da mesma classe” (Q 22, \$3, p. 2148, grifo adicionado). Por esse motivo, a "função econômica da reprodução" não poderia ser pensada apenas como "fato geral", de combinação demográfica suficiente para equilíbrio e manutenção da "parte passiva da população (passiva no sentido normal, por idade, invalidez etc."), mas encarada também como fenômeno "molecular", ou seja, "interno aos pequenos agregados econômicos como a família” (Idem, ibidem).

As mulheres, aqui, apareceram deslocadas em relação à "parte passiva normal” da população, e a família emerge como um "agregado econômico" específico no qual se desenvolvem os conflitos "moleculares" da função reprodutiva. Dessa constatação, Gramsci avançou a ideia, original em relação ao texto de 1930, de que a "formação de uma nova personalidade" é o aspecto mais importante da "questão ético-civil" ligada à questão sexual: a conquista de "não apenas uma real independência do homem, mas uma nova forma de conceber a si mesma e a sua parte nas relações sexuais" (Idem, p. 2149, grifo nosso). Na recuperação da resenha sobre o livro de Ludovici 
a respeito do feminismo ( $\mathrm{Q} 22, \$ 9, \mathrm{p} .2160$ ), Gramsci insistiu neste como produto contraditório das tentativas burguesas fracassadas de regular a questão sexual.

No Quaderno 22, sendo a questão feminina uma questão política - e não puramente econômica ou demográfica -, Gramsci explorou de maneira mais complexa o terreno em que ela se desenvolve. Na reescrita do Q $1, \$ 158$ - agora Q $22, \$ 10$-, insistiu nos efeitos "estratificados" (não mais de uma classe em particular) da crise sexual e, particularmente, do "contágio" que as classes trabalhadoras sofrem nesse processo (Q 22, $\$ 10$, pp. 2162-2163). De maneira inédita em relação à primeira redação do texto, concluiu que a única forma de confrontar o problema seria por meio de uma coerção de novo tipo, "exercida por uma elite de uma classe sobre a própria classe” (Idem, p. 2163). A formação dessa elite, identificada principalmente pela capacidade de autocoerção e autodisciplina, seria a única maneira de confrontar a "mentalidade iluminista e libertária nas esferas das relações sexuais" e suplantar a emergência da "hipocrisia social totalitária" (Idem, pp. 2163-2164).

O percurso da "questão feminina" no pensamento de Gramsci evidencia o crescimento de sua dimensão política e histórico-cultural. Esse duplo caráter, aliás, se evidenciou na conexão entre dois cadernos especiais escritos no mesmo período, o Quaderno 22 e o Quaderno 25. Neste último, Gramsci discutiu, especificamente, o “desenvolvimento histórico dos grupos sociais subalternos". Foi aqui, aliás, que o conceito de subalterno, muito menos desenvolvido nos escritos carcerários se comparado ao de hegemonia ${ }^{14}$, adquiriu centralidade analítica inédita. Nele, Gramsci viabilizou teoricamente o binômio histórico-político-filosófico da "hegemonia-subalternidade", fundamental para compreender o pensamento gramsciano em sua fase mais tardia. No Q $25, \$ 4$, Gramsci apresentou a ideia de que, em comum, todos os grupos subalternos "carecem de autonomia", agem sempre "na defensiva”, "são constrangidos por leis de necessidade", o que faz sua ação e pensamento sempre "mais limitados" em relação às "leis de necessidade das classes dominantes" (Q 25, \$4, p. 2286). Nesse caso, continuou, a "questão das mulheres" poderia ser equiparada à de qualquer outro grupo subalterno. Pensar a "questão feminina", portanto, seria pensar antes de mais nada a história de uma condição subalterna.

Apesar disso, Gramsci notou limites para a comparação entre a condição subalterna feminina e as possibilidades da hegemonia do presente. Afinal, a característica original da emergência do Estado moderno era o processo de substituição de um antigo "bloco mecânico dos grupos sociais", subordinados ao poder do senhor (de escravos, servos ou o patriarca), por uma subordinação progressiva de tipo novo, à

14. Para interpretações do feminismo a partir do conceito gramsciano de hegemonia, ver Ledwith (2009), Slaughter (2011) e Przybylowicz (1990). 
"hegemonia ativa do grupo dirigente e dominante" (Idem, p. 2287). Um processo que, por um lado, abolira formas de autonomia que os antigos grupos sociais detinham (territorial, cultural, religiosa, por exemplo), que renasciam "de outra forma, como partidos, sindicatos, associações de cultura” (Idem, ibidem).

\section{Apontamentos}

Em seus escritos mais tardios da prisão, Gramsci desenvolveu a ideia de que o aspecto central da modernidade é a absorção pelas "ditaduras contemporâneas" de toda e qualquer "forma de autonomia". As formas contemporâneas de domínio não se caracterizavam pela oposição frontal do Estado em relação a uma ou outra forma de autonomia, mas pelo esforço de "acentramento legal de toda a vida nacional nas mãos do grupo dominante, que se torna 'totalitário" (Idem, ibidem). Não seria possível, portanto, devolver a nenhum grupo social subalterno "histórico" uma qualidade intrinsecamente autônoma de confronto hegemônico. Nem aos novíssimos grupos subalternos - o proletariado urbano, por exemplo - e menos ainda aos grupos de condição subalterna anterior ao capitalismo, entre os quais as mulheres.

Ao contrário do que já se afirmou a respeito do "marxismo" de Gramsci e a questão feminina ${ }^{15}$, portanto, esta teve um papel-chave em seu pensamento, atuando como força propulsora de uma elaboração teórica nova (Durante 2008; 2012; Slaughter, 2011). Nesta, o limite da condição feminina como condição antagonista era pensado em uma chave fundamentalmente histórico-política. A subalternidade, como condição histórica, poderia ser acumulada mas nunca dividida ou isolada. Em outras palavras, a questão feminina marcaria de maneiras diversas e profundas a experiência humana, mas esta não poderia ser reduzida àquela sem um alto preço a ser pago. $\mathrm{O}$ limite da analogia histórica era também o dilema da ação política.

Referências Bibliográficas

Alloisıo, Mirella \& Ajo', Marta. (1978), La donna nel socialismo italiano: tra cronaca e storia (1892-1978). Cosenza, Edistampa.

Bortolotti, Franca Pieroni. (1963), Alle origini del movimento femminile in Italia (18481892). Turim, Giulio Einaudi.

Bortolotti, Franca Pieroni. (1978), Femminismo e partiti politici in Italia (1919-1926). Roma, Editori Riuniti.

15. Ver, por exemplo, Moe (1990) Mancina (1987) e Garcia, (1992). 
Bortolotti, Franca Pieroni. (1977), “Gramsci e la questione femminile”. In: Ferri, Franco (ed.). Politica e storia in Gramsci: atti del convegno internazionale di studi gramsciani [Firenze, dic. 1977]. Roma, Editori Riuniti, vol. 2.

CAmparini, Aurelia. (1991), "Il rapporto uomo-donna nel dibattito marxista degli anni venti". Critica Marxista, 2: 119-130.

Chataway, Teresa. (1995), “Giulia Gramsci: democracy and the 'sexual question”". Australian Journal of Political Science, 30 (1): 120-136.

Donno, Ada. (2008), “Gramsci, uguaglianza e la differenza”. In: Centro GramsCi Di EduCAZIONE E di Cultura. L'educazione gramsciana: $70^{\circ}$ Gramsci parlamentare unitario: convegno di Roma, giugno 2007. Teramo, Edizioni Nuova Cultura, pp. 121-124. Disponível em: http://www.centrogramsci.it/edizioni/pdf/educ_gramsciana.pdf.

Durante, Lea. (2012), “Gramsci e la soggettività politica delle donne tra natura e storia”. Critica Marxista, 1: 57-66.

Durante, Lea. (2008), “La 'riforma intellettuale e morale' e la 'formazione di una nuova personalità femminile'”. Critica Marxista, 2-3: 37-43.

FIori, Giuseppe. (2003), La vita di Antonio Gramsci. Nuoro, Ilisso Edizioni.

Gabrielli, Patrizia. (1989), "Le origini del movimento femminile comunista in Italia 19211925”. Critica Marxista, 5: 103-132.

García, Veronica Vazquez. (1992), "Gramsci, women, and the state”. Alternate Routes, 9: 1-25.

Goldman, Wendy. (2014), Mulher, Estado e revolução: politica da familia soviética e da vida social entre 1917 e 1936. São Paulo, Boitempo.

Gramsci, Antonio. (1969), L'Ordine Nuovo: 1919-1920, 1924-1925. Milão, Edizioni del Calendario $[\mathrm{ON}]$.

GramsCi, Antonio. (1971), La costruzione del partito comunista: 1923-1926. Turim, Einaudi [CPC].

Gramsci, Antonio. (2009), Epistolario: 1906-1922. A cura di David Bidussa, Francesco Giasi, Gadi Luzzatto Vogghera e Maria Luisa Righi. Roma, Istituto della Enciclopedia Italiana, vol. $1[\mathrm{E}]$.

Gramsci, Antonio. (1996), Letere dal carcere. 1926-1937. A cura di Antonio A. Santucci. Palermo, Sellerio [LC].

Gramsci, Antonio. (1975), Quaderni del carcere. A cura di Valentino Gerratana. Turim, Einaudi, 4 vols.

Gramsci, Antonio. (1982), La Città Futura. Turim, Einaudi [CF].

Honeycut, Karen. (1981), "Clara Zetkin: A socialist approach to the problem of women's oppression". In: Slaughter, Jane \& KERN, Robert (eds.). European women on the left: socialism, feminism and the problems faced by political women, 1880 to the present. Westport/ Connecticut, Greenwood Press.

LANDEs, Joan. (1981), “Feminism and the internationals”. Telos, 1981 (49): 117-126. 
Ledwith, Margaret. (2009), "Antonio Gramsci and feminism: the elusive nature of power". Educational Philosophy and Theory, 41 (6): 684-697.

Lenin, V. I. ([1934] 1969), The emancipation of women. Nova York, International Publishers. Ludovici, Anthony. (1923), Woman. A vindication. Bombay/Sidney, Constable.

Mancina, Claudia. (1987), “Teoria dell'identità e questione femminile”. Critica Marxista, 2-3: $177-193$.

Moe, Nelson J. (1990), "Production and its others: Gramsci’s 'sexual question". Rethinking Marxism: A Journal of Economics, Culture \& Society, 3 (3-4): 218-237.

Mussi, Daniela. (2017), “O incômodo de Kollontai: a Revolução Russa e as prostitutas”. Revista Socialismo e Liberdade, 20: 52-57.

Orioles, Vincenzo. (2002), Percorsi di parole. Roma, Il Calamo.

Przybylowicz, Donna. (1989-1990), “Toward a feminist cultural criticism: hegemony and modes of social division”. Cultural Critique, 14: 259-301.

Ravera, Camilla. (1973), Diario di trentanni, 1913-1943. Roma, Editori Riuniti.

Rosengarten, Frank. (1984-1985), “The Gramsci-Trotsky Question (1922-1932)”, Social Text, 11: 65-95.

Slaughter, Jane. (2011), "Gramsci's place in women's history". Journal of Modern Italian Studies, 16 (2): 256-272.

Turati, Filippo. (2 nov. 1919c.), "Il voto alla donna e le salariate dell'amore”. La Difesa delle Lavoratrici, VIII (19): 2-3, parte 3.

Turati, Filippo. (19 out. 1919b), "Il voto alla donna e le salariate dell'amore”. La Difesa delle Lavoratrici, viII (18): 2-3, parte 2.

Turati, Filippo. (5 out. 1919a.), "Il voto alla donna e le salariate dell'amore”. La Difesa delle Lavoratrici, viII (17): 2-3, parte 1.

Zetrin, Clara. (1929), Reminiscences of Lenin. Londres, Modern Books. 


\section{Resumo}

\section{Antonio Gramsci e a questão feminina}

Desde os primeiros meses de redação dos Quaderni del Carcere, Gramsci escreveu sobre a centralidade da "salvaguarda da personalidade feminina" no contexto de crise capitalista que se desdobrava a partir da Primeira Guerra Mundial. Nesse sentido, o presente artigo procura responder duas questões: (a) quais as possíveis fontes para a formulação de Gramsci nos escritos carcerários sobre o papel político da questão feminina? (b) como essa formulação se desenvolveu em seu pensamento na prisão ao longo do tempo? A pesquisa reconstrói os caminhos desse problema nos escritos gramscianos anteriores e posteriores ao cárcere, explorando em especial o tratamento não economicista do mesmo. Discute, ainda, a importância da experiência pessoal de Gramsci, prisioneiro do regime fascista, para um desenvolvimento teórico da questão feminina como condição subalterna.

Palavras-chave: Antonio Gramsci; Questão feminina; Feminismo; Fascismo.

\section{Abstract}

\section{Antonio Gramsci and the feminine question}

From the first months of the writing of the Quaderni del Carcere, Gramsci wrote about the centrality of the "safeguard of the female personality" in the context of a capitalist crisis that unfolded after World War I. Departing from this idea, the present article proposes to answer two questions: (a) What are the possible sources for Gramsci's formulation in the prison writings on the political role of the feminine question? (b) How did this formulation develop along the prison notebooks? The text reconstructs the appearance of this subject in Gramsci's writings before the imprisonment and after, exploring its specificities. It also discusses the importance of the personal experience of Gramsci, prisoner of the fascist regime, for a theoretical development of the feminine question as subaltern condition.

Keywords: Antonio Gramsci; Feminine question; Feminism; Fascism.

Texto recebido em 5/5/2019 e aprovado em 7/5/2019.

DoI: $10.11606 / 0103-2070 . t s .2019 .157731$

Daniela Mussi é pós-doutoranda do Departamento de Ciência Política da Universidade de São Paulo (USP). Bolsista Capes-PNPD. E-mail: danixhm@gmail.com. 